Check for updates

Cite this: RSC Adv., 2019, 9, 40051

Received 5th October 2019

Accepted 28th November 2019

DOI: $10.1039 / c 9 r a 08079 a$

rsc.li/rsc-advances

\section{Fabrication of stable superabsorbent hydrogels for successful removal of crystal violet from waste water $\dagger$}

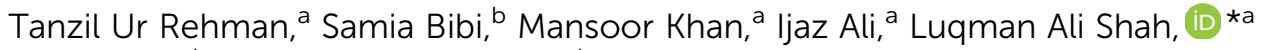 \\ Abbas Khan ${ }^{\mathrm{b}}$ and Muhammad Ateeq ${ }^{\mathrm{b}}$
}

Smart superabsorbent hydrogels consisting of acrylamide/sodium alginate (AS), acrylamide/sodium alginate/2-acrylamido-2-methylpropane sulphonic acid (ASA $A_{x} x=$ amount of AMPS) were synthesized via free radical polymerization. The swelling behavior of the hydrogels was studied in distilled and tap water. It was found that by increasing the amount of 2-acrylamido-2-methylpropanesulphonic (AMPS) in the hydrogel composition, the hydrogel swelling capability was enhanced from $3685 \%$ for AS to $4797 \%$ for $\mathrm{ASA}_{1}$ and $21175 \%$ for $\mathrm{ASA}_{2}$ in distilled water, while in tap water this property varied from $915 \%$ for $\mathrm{AS}$ to $988 \%$ and $1588 \%$ for $\mathrm{ASA}_{1}$ and $\mathrm{ASA}_{2}$, respectively. All the samples were found to be efficient for the removal of crystal violet from aqueous solution. The absorption efficiency and \% removal increased from $1.78 \mathrm{mg} \mathrm{g}^{-1}$ and $62.6 \%$ for AS to $3.31 \mathrm{mg} \mathrm{g}^{-1}$ and $75 \%$ for $\mathrm{ASA}_{1}$ and $3.34 \mathrm{mg} \mathrm{g}^{-1}$ and $82.1 \%$ for $\mathrm{ASA}_{2}$. The effects of $\mathrm{pH}$, contact time, initial dye concentration and hydrogel dosage on the removal process were studied in detail. The mechanism of CV removal occurs according to the Freundlich isotherm following pseudo second order kinetics. The thermodynamic parameters showed that the sorption process is spontaneous and endothermic in nature. The superabsorbent hydrogels were regenerated and reused in six consecutive cycles with $5 \%$ decrease in efficiency.

\section{Introduction}

Various industries, like textile, ${ }^{1,2}$ paint, ${ }^{3,4}$ pharmaceutical, ${ }^{5}$ and food, ${ }^{6}$ are the direct contributors of pollutants like dyes, ${ }^{7}$ heavy metal ions $^{8,9}$ and other organic pollutants ${ }^{10}$ to water. These pollutants are toxic and cause severe health problems in human beings and also seriously affect aquatic life. ${ }^{11}$ Therefore proper treatment of industrial water is required before discharging into water sources. Besides the development of new techniques and materials such as ozonation, ${ }^{12,13}$ advanced oxidation, ${ }^{14,15}$ catalysis, ${ }^{16,17}$ osmosis, ${ }^{18,19}$ adsorption, ${ }^{20,21}$ polymer hydrogels,${ }^{22}$ activated carbon, ${ }^{23}$ and superabsorbents, ${ }^{24}$ water treatment is still a hot area of research.

Currently, due to simple synthesis process, high efficiency, environmental friendly and quick recoverability made superabsorbent hydrogels to be used for waste water treatment in terms of both organic and inorganic pollutants. ${ }^{25,26}$ The superabsorbent hydrogels are 3D cross-linked polymer network materials which can imbibe a huge amount of water inside its

${ }^{a}$ Polymer Laboratory, National Centre of Excellence in Physical Chemistry University of Peshawar, Peshawar 25120, Pakistan. E-mail: luqman_alisha@yahoo.com; Luqman_alisha@uop.edu.pk; Fax: +92919216671; Tel: +92919216766 ${ }^{b}$ Department of Chemistry, Abdul Wali Khan University, Mardan, Pakistan

$\dagger$ Electronic supplementary information (ESI) available. See DOI: $10.1039 / \mathrm{c} 9 \mathrm{ra} 08079 \mathrm{a}$ network. The swelling behavior and active charges on the network of superabsorbent hydrogels are responsible for the removal of pollutants from waste water. Therefore, the composition of hydrogels required a key consideration in its synthesis. The introduction of monomers in hydrogel for enhancing the swelling property is mostly due to ionizable hydrophilic groups which are responsive in nature. ${ }^{27}$ The synthesis of superabsorbent hydrogels with different monomer contribution is also carried out for the betterment of its properties. In previous study, we have prepared zwitterionic superabsorbent hydrogels based on cationic monomer 3acrylamidopropyl trimethylammoniumchloride (APTMACl) and anionic monomer AMPS. The materials were applied for $\mathrm{CV}$ and Congo red (CR) removal from waste water and found efficient. ${ }^{28}$ In another study acrylamide and acrylicacid based superabsorbent hydrogels were synthesized in different monomer composition, and successfully applied for few selected heavy metal ions removal. ${ }^{29}$ But the low mechanical strength and fracturing, limits their applications to be used for a long time (in months) in aqueous medium. Therefore, the development of smart materials with superabsorption capacity and large mechanical stability is still a challenging task and needs a proper attention.

The AMPS is an anionic pH sensitive monomer consist of cleavable active sulphonic acid group $\left(-\mathrm{SO}_{3} \mathrm{H}\right)$. The protonation and deprotonation of $-\mathrm{SO}_{3} \mathrm{H}$ takes place with change in $\mathrm{pH}$ of 
the medium from the $\mathrm{pKa}$ value of AMPS, due to which the polymer network undergoes swelling and de-swelling transition. ${ }^{30}$ The acidic groups also increase the hydrophilicity of the polymeric network thus increase the swelling behavior more and can be applied for absorption of dyes, heavy metal ions and other organic pollutants. ${ }^{31}$ The fabrication of AMPS in acrylamide/sodiumalginate hydrogels is expected to produce superabsorbents with intense swelling behavior, prolong mechanical stability and high removal capability towards organic dyes.

In this paper we concentrate on the development of superabsorbent hydrogels with extra ordinary high swelling and mechanical behavior, by fabrication different amount of a $\mathrm{pH}$ sensitive monomer 2-acrylamido-2-methylpropane sulphonic acid (AMPS) in acrylamide/sodiumalginate hydrogel. The increase in AMPS amount in hydrogel composition introduces a high swelling capacity in hydrogels in both distilled and tap water. The superabsorbent hydrogels showed enhanced mechanical strength and remained stable in water for months without any fracture (physically confirmed). The superabsorbent hydrogels were further tested in the sorption process of toxic crystal violet (CV) from aqueous medium at different environmental conditions in detail. The materials were found more efficient and can be regenerated easily for further purification process. This study will open a new understanding for researchers to fabricate a new materials for waste water treatment in future.

\section{Experimental}

\subsection{Materials}

Acrylamide (AAm, BDH), sodium alginate (SA, Daejung Korea), 2-acrylamido-2-methylpropane sulfonic acid (AMPS, Alfa Aesar), $N, N^{\prime}$-methylenebisacrylamide (MBA, BDH), ammonium persulphate (APS, Sigma Aldrich), phosphate buffers ( $\mathrm{pH}=3,7$ and 9, Daejung Korea), crystal violet (CV, Sigma Aldrich), $\mathrm{NaNO}_{3}$ (Merck), $\mathrm{NaOH}(\mathrm{BDH})$ and $\mathrm{HCl}$ (Sigma) reagents were used as received in this work. Milli-Q double deionized distilled water was used for all experimental work.

\subsection{Synthesis of the superabsorbent hydrogels}

In the current study the superabsorbent hydrogels were synthesized in a single step using the chemical crosslinking agent (MBA) and thermo-initiator (APS). Initially, the AAm monomer $(4 \mathrm{~g})$ and SA polymer $(0.5 \mathrm{~g})$ in a ratio of $8: 1$ respectively were dissolved in $28 \mathrm{ml}$ of deionized water in a reaction vessel for $4 \mathrm{~h}$. The MBA, $0.25 \%$ with respect to the weight of AAm was added to the solution of AAm/SA and stirred for $30 \mathrm{~min}$ to obtain a transparent homogeneous solution. Finally, the APS solution $0.05 \mathrm{~g} 2 \mathrm{ml}^{-1}$ of $\mathrm{H}_{2} \mathrm{O}$ was added and stirred the solution for $10 \mathrm{~min}$. The solution was put in a Petri dish and placed in an oven at $60{ }^{\circ} \mathrm{C}$ for $3 \mathrm{~h}$ to complete the polymerization process. After $3 \mathrm{~h}$, the prepared hydrogels were collected and cut into desired shape, the silicon oil was sprayed on the hydrogels to retain the water molecules inside the gel matrix. The sample was coded as AS and saved for further use at ambient temperature.

2-Acrylamido-2-methylpropane sulfonic acid (AMPS) functionalized AS hydrogels were prepared by the same procedure with different amount of AMPS, $0.12 \mathrm{~g}$ and $0.25 \mathrm{~g}$. Here the amount of MBA was added with respect to both AAm and AMPS. These samples were coded as $\mathrm{ASA}_{1}$ and $\mathrm{ASA}_{2}$, where $\mathrm{A}_{1}$ and $\mathrm{A}_{2}$ represent the $0.12 \mathrm{~g}$ and $0.25 \mathrm{~g}$ weight of AMPS respectively used in the feed composition.

\subsection{Characterization}

The samples $\mathrm{AS}, \mathrm{ASA}_{1}$ and $\mathrm{ASA}_{2}$ were characterized by gravimetric method for swelling investigation, FT-IR spectra were recorded using PerkinElmer Spectrum version 10.5.1, which provides information about the functional groups existence in hydrogels network and confirms the formation. Scanning Electron Microscopy (SEM, JSM-5910, JEOL) was performed for elucidation of surface morphology of the materials. The absorbance of the CV in aqueous medium was found by UVVisible spectrophotometer (UV-2100).

\subsection{Swelling ratio}

The gravimetric method was used to investigate the water absorption capacity ${ }^{32}$ of the hydrogels in distilled as well as in tap water at different $\mathrm{pH}$. The hydrogels were cut into small pieces having length and width of $1 \mathrm{~cm}$ and dry at ambient temperature for two days. Once the hydrogels are completely dry, then the weighted sample was placed in distilled and tap water. With different intervals of time the hydrogels were taken out from the water, the surface water was removed with tissue paper and increase in the weight was noted. The percent swelling was calculated from eqn (1);

$$
\text { Percent swelling }=\frac{w_{\mathrm{s}}-w_{\mathrm{d}}}{w_{\mathrm{d}}} \times 100
$$

where $w_{\mathrm{s}}$ representing the weight of the swollen hydrogels and $w_{\mathrm{d}}$ is the weight of dried hydrogels.

\subsection{Absorption study}

Batch absorption experiments were performed to check the removal performance of superabsorbent hydrogels towards CV in aqueous medium. A typical amount of superabsorbent hydrogels were taken and placed in CV solution with known concentration. The experiments were performed at room temperature given $16 \mathrm{~h}$ equilibrium time. The concentration of the CV was found by measuring the absorption intensity at $\lambda_{\max }=588 \mathrm{~nm}$ with intervals of time. The provided conditions for each experiment is mentioned in each caption of the figures.

\section{Results and discussion}

\subsection{Characterization of hydrogels before and after CV absorption}

The samples $\mathrm{AS}, \mathrm{ASA}_{1}$ and $\mathrm{ASA}_{2}$ were characterized by FT-IR spectroscopy as shown in Fig. $\mathrm{S} 1 . \dagger$ The analysis were based 
on, before and after absorption of CV dye by each sample. In sample AS, two peaks at $1600 \mathrm{~cm}^{-1}$ and $1649 \mathrm{~cm}^{-1}$ were found which show $\mathrm{N}-\mathrm{H}$ bending vibration and $\mathrm{C}=\mathrm{O}$ stretching vibration, while $1320 \mathrm{~cm}^{-1}$ indicate the bending vibrations due to the presence of $\mathrm{NH}-\mathrm{CO}$ group (amide) and $-\mathrm{NH}$ group respectively. The $\mathrm{C}=\mathrm{O}$ asymmetrical brooding peak were found at $1650 \mathrm{~cm}^{-1}$ which is due to the bending mode of $\mathrm{O}-\mathrm{H}$ strongly adhered molecules of water. ${ }^{33}$ Similarly, the $\mathrm{N}-\mathrm{H}$ primary amine bending were mostly reported in the range of $1590-1650 \mathrm{~cm}^{-1}$ by the workers. ${ }^{34}$ The decrease in intensity and slight shifting in the peak at $1260 \mathrm{~cm}^{-1}$ in hydrogels after absorption of CV shows the interaction of $\mathrm{C}-\mathrm{N}$ group of copolymer hydrogels with $\mathrm{CV}$ molecules.

The new peak in FTIR spectra for $\mathrm{ASA}_{1}$ and $\mathrm{ASA}_{2}$ at $1173 \mathrm{~cm}^{-1}$ compared to AS, is due to bending vibration of $-\mathrm{SO}_{3}$ group and confirms the functionalization of AMPS in ASA hydrogels. However, after absorption of $\mathrm{CV}$, this peak disappeared and shows the existence of interactions between $-\mathrm{SO}_{3}$ group of AMPS and CV molecules. Other peaks were found at $3336 \mathrm{~cm}^{-1}$ and $3177 \mathrm{~cm}^{-1}$ which are due to stretching vibration of -OH and -CO-OH groups respectively. The peak at $2941 \mathrm{~cm}^{-1}$ is for asymmetric stretching vibration of $-\mathrm{CH}_{2}$ groups present in the chain.

SEM analysis was performed to investigate the morphology of prepared materials and results are given in Fig. 1. Before absorption of $\mathrm{CV}$, the surface of sample AS was rough and porous (Fig. 1a), the roughness and porosity was further enhanced with the incorporation of AMPS in ASA $_{1}$ (Fig. 1b) and $\mathrm{ASA}_{2}$ (Fig. 1c) samples. Therefore, the removal capability of samples towards $\mathrm{CV}$ in aqueous environment follow $\mathrm{ASA}_{2}>$ $\mathrm{ASA}_{1}>\mathrm{AS}$ order. The SEM analysis was also performed after absorption of dye molecules and results are given in Fig. 1(d-f), which shows the homogenous smooth surface for all hydrogels. It is because of occupying the surface active sites of hydrogels by CV molecules. Thus SEM is the key characterizing tools for the surface texture, surface shape, smoothness and surface porosity of the synthesized materials. ${ }^{35}$

\subsection{Swelling properties}

Fig. 2 shows the swelling properties of the superabsorbent hydrogels determined in both distilled and tap water. The results clearly indicate the super absorptive nature of the hydrogels in both types of water. According to our expectations, the addition of AMPS was very effective in case of absorption for both, but particularly to distilled water. The results shown in Fig. 2, clearly indicate that addition of AMPS increased the capability of the superabsorbent hydrogel to take up (swell) a lot of water (Fig. 2a), which varied from $3685 \%$ (AS) to $4797 \%$ $\left(\mathrm{ASA}_{1}\right)$ and 21 175\% ( $\left.\mathrm{ASA}_{2}\right)$ in distilled water (Fig. 2b), and from $915 \%$ (AS) to $988 \%$ and $1588 \%$ for $\mathrm{ASA}_{1}$ and $\mathrm{ASA}_{2}$ respectively in tap water (Fig. 2c). The Fig. 2a and Video S1 $\uparrow$ also confirm the stability and mechanical strength of these materials, because after one month in water, the hydrogels not underwent any rupture.

The swelling behavior of the hydrogels depends on the ionizable groups attached with the backbone of the polymer hydrogel. Hydrogels with more ionizable groups show enhanced swelling capacity compared to non ionizable group's hydrogels. Furthermore density of crosslinking also affect the swelling properties of hydrogels in inverse manner. ${ }^{36,37}$ In the present study these ionizable groups are also responsible for the absorption of distilled water. Initially, AS consist of acrylamide
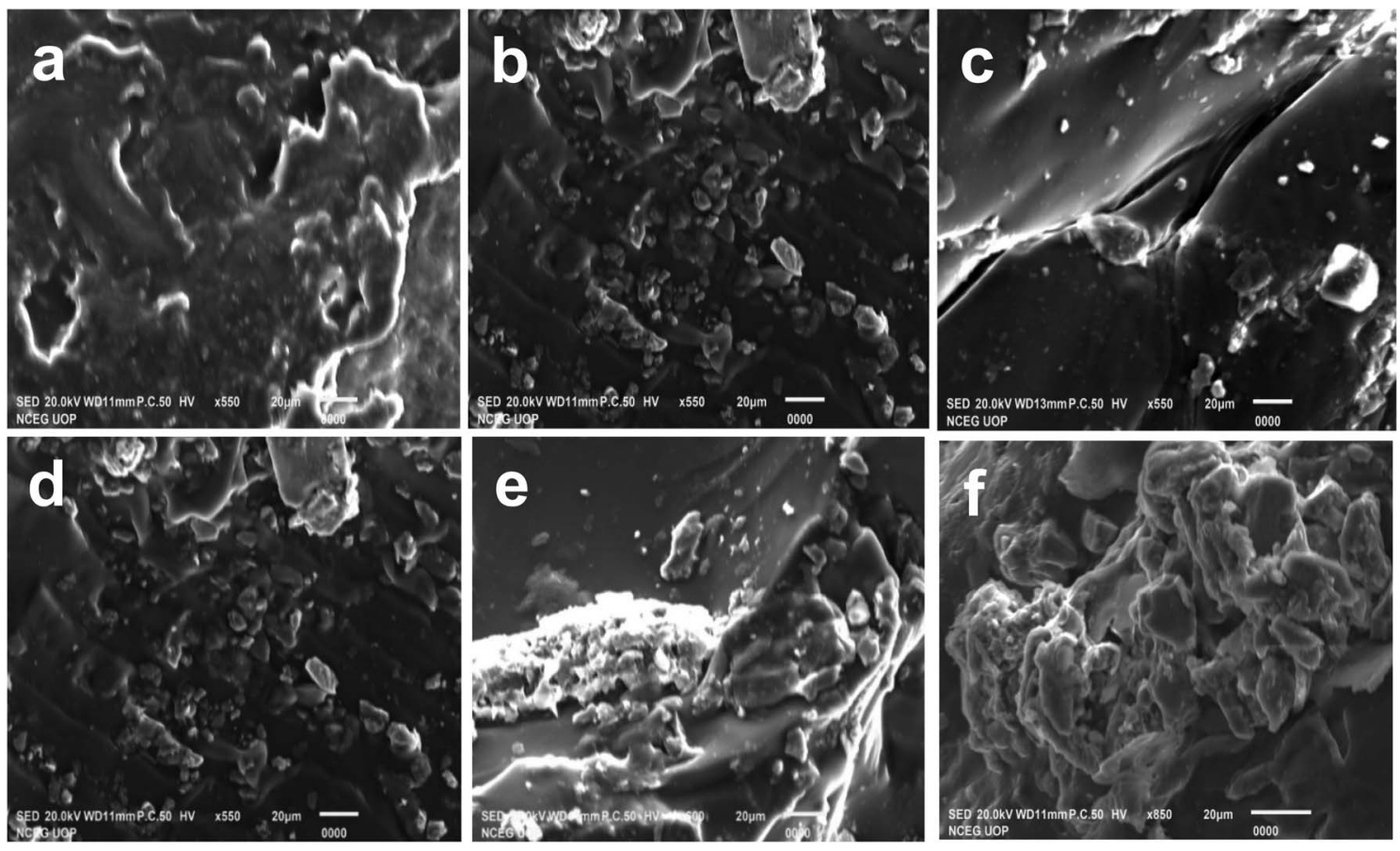

Fig. 1 SEM images of samples before absorption of CV (a) AS, (b) $A_{S A}$, (c) $A_{S A}$ and after absorption of CV (d) AS, (e) ASA 1 and (f) ASA 

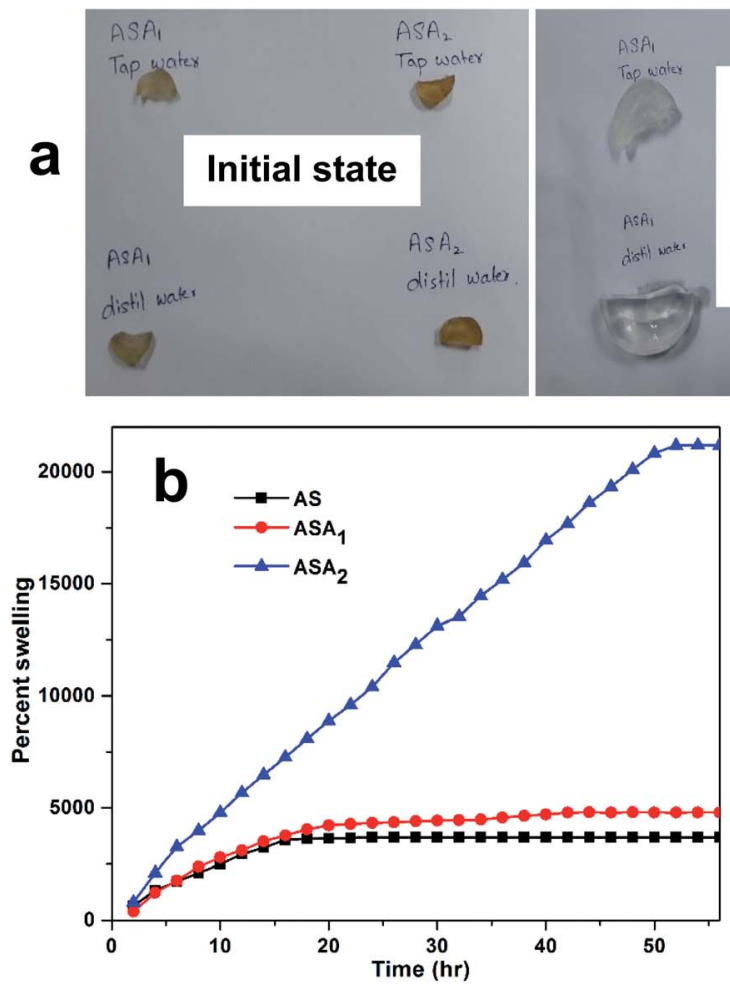
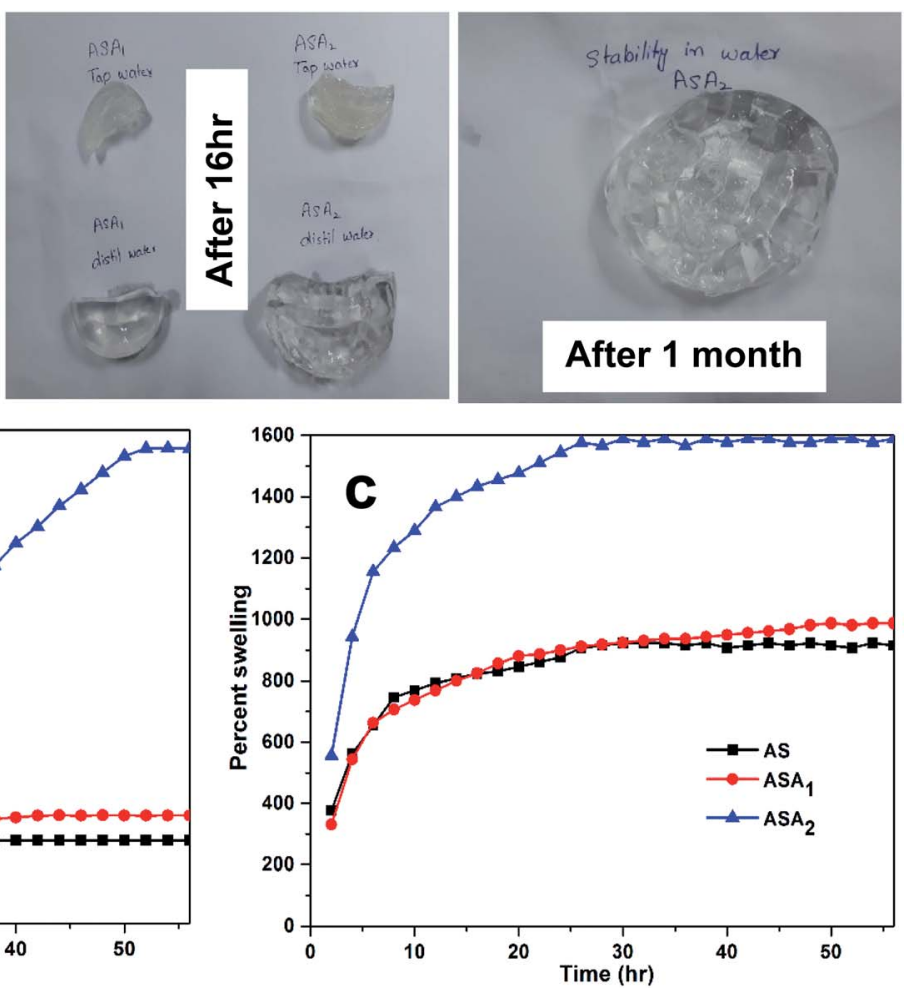

Fig. 2 (a) Physical changes in superabsorbent hydrogels during swelling and the percent swelling behavior in (b) distilled and (c) tap water.

and alginate, in which acrylamide contains non ionizable groups, while alginate contains carboxylic functional groups which is hydrophilic in nature, and deprotonated in distilled water and produce the electrostatic repulsion between carboxylic groups, due to which the hydrogel swells enough. ${ }^{38}$ As discussed above the addition of AMPS $(0.12 \mathrm{~g})$ enhance the water absorption capability of the hydrogel the reason behind this capability is that AMPS consist of $-\mathrm{CONH}$ and $-\mathrm{SO}_{3} \mathrm{H}$ groups which are the hydrophilic groups and produce additive effect by carboxylic group of sodium alginate and as a result the water up takes capability increase. Further increase in AMPS (0.25) amount were further increase the water absorption due to the number of hydrophilic groups present in AMPS. ${ }^{39,40}$

\subsection{Absorption study}

3.3.1. Point of zero charge (PZC) and effect of $\mathrm{pH}$ on the absorption of CV. PZC is the value at which the surface of the materials becomes zero and all the active sites remains neutral. The PZC of sample AS, $\mathrm{ASA}_{1}$ and $\mathrm{ASA}_{2}$ were determined by putting $0.1 \mathrm{~g}$ of each sample in $30 \mathrm{ml}$ of $0.1 \mathrm{~N} \mathrm{NaNO}_{3}$ solution. Each solution was distributed in 11 bottles with different $\mathrm{pH}$ ranging from 2-11. The $\mathrm{pH}$ of each bottle was adjusted by $0.1 \mathrm{M}$ $\mathrm{NaOH}$ and $0.1 \mathrm{M} \mathrm{HNO}_{3}$ solution and monitored by $\mathrm{pH}$ meter (pH-2106). The bottles were shakeup in shaker and then leave the bottles for $24 \mathrm{~h}$. The final $\mathrm{pH}$ of the bottles were determined and noted by $\mathrm{pH}$ meter and the PZC of the all the three samples was calculated by using equation $\Delta \mathrm{pH}=\mathrm{pH}_{\mathrm{i}}-\mathrm{pH}_{\mathrm{f}}{ }^{{ }^{11}}$ Where $\mathrm{pH}_{\mathrm{i}}$ is the initial $\mathrm{pH}$ and $\mathrm{pH}_{\mathrm{f}}$ is the final $\mathrm{pH}$ of the solution.
The PZC of sodium alginate was found $\mathrm{pH}_{\mathrm{zpc}}=7.5$, below this value the surface become positively charged and above which the surface acquired negative charge for the removal of positive dyes. ${ }^{41}$ The acrylamide affects the PZC of sodium alginate and due to the less $\%$ age of alginate and greater $\%$ age of acrylamide lowers the value of PZC to 7.06, 6.7 and 6.1 for AS, $\mathrm{ASA}_{1}$ and $\mathrm{ASA}_{2}$ respectively (Fig. 3a). The absorption and removal of the $\mathrm{CV}$ from aqueous medium by superabsorbent hydrogels occurs by two processes. First one is the diffusion of $\mathrm{CV}$ in the network of hydrogels with the penetration of water molecules and second process is associated with the electrostatic attractive forces. The $\mathrm{pH}$ has a considerable and observable effect on the absorption process of dye. The Fig. $3 \mathrm{~b}$ shows that removal ability of all the samples increases with increase in $\mathrm{pH}$ of the medium, but at the point of PZC for all the samples the \% removal slightly decreases due to the isoelectric point. The \% removal at this stage is due to the swelling of the gel which compels the dye to diffuse within the gel network along with water. After PZC the \% removal increased abruptly because of the availability of negative sites on the hydrogel network. The maximum absorption and \% removal of the dyes by each sample depends on the amount of negative sites on the hydrogels. The \% removal for AS increased from $60 \%$ to $65.7 \%$ and decreased to $64 \%$ at $\mathrm{pH}<\mathrm{PZC}(\mathrm{pH} 7.06)$ and again reached to $72 \%$ at $\mathrm{pH} 11$, which is due to diffusion and electrostatic attractions between dye and polymer network. The \% removal of $\mathrm{ASA}_{1}$ decreased from $70 \%$ to $68.7 \%$ at $\mathrm{pH}=\mathrm{PZC}(\mathrm{pH} 6.7)$ and immediately increased from $68.7 \%$ to $83 \%$ with increasing $\mathrm{pH}$ values due to the appearance of negative charge on hydrogel 

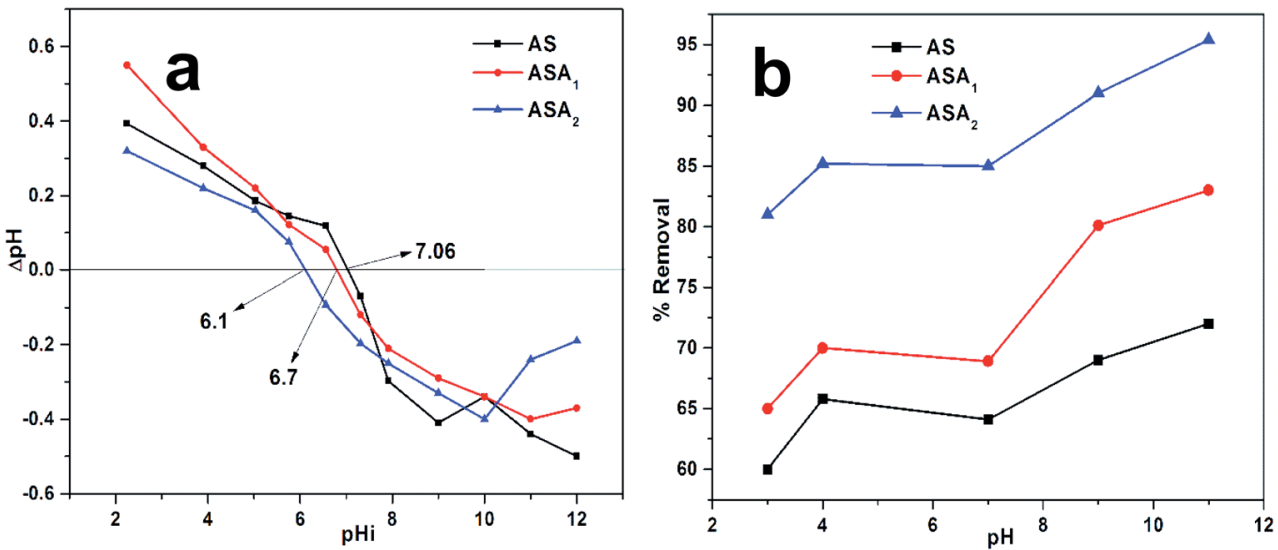

Fig. 3 (a) Point of zero charge (PZC) and (b) effect of $\mathrm{pH}$ on the \% removal of $\mathrm{CV}$ by superabsorbent hydrogels. Conditions for PZC: temperature $25^{\circ} \mathrm{C}$, dose $0.1 \mathrm{~g} \pm 0.05$, equilibrium time $24 \mathrm{~h}$, pH range (2-11) adjusted by $0.1 \mathrm{M} \mathrm{HNO}_{3}$ and $\mathrm{NaOH}$, using $\mathrm{NaNO}_{3} 0.1 \mathrm{~N}$ solution and volume taken $30 \mathrm{ml}$.

network. Similarly, for sample $\mathrm{ASA}_{2}$ the \% removal increased from $81 \%$ to $85.2 \%$ at $\mathrm{pH}<\mathrm{PZC}$ ( $\mathrm{pH} 6.1$ ), then again decreased to $84.7 \%$ at $\mathrm{pH}=\mathrm{PZC}$ ( $\mathrm{pH} 6.1$ ) and then increased to $95.4 \%$ at $\mathrm{pH} 11$. The \% removals of all samples were calculated by using eqn (2);

$$
\% \text { removal }=\frac{\left(C_{\mathrm{o}}-C_{\mathrm{e}}\right)}{C_{\mathrm{o}}} \times 100
$$

where $C_{\mathrm{o}}$ is the initial concentration (ppm) and $C_{\mathrm{e}}$ is the concentration (ppm) of dye at equilibrium.

3.3.2. Effect of superabsorbent dosage. The dosage effect for all superabsorbent hydrogels on removal of CV was investigated by taking different amount of $\mathrm{AS}, \mathrm{ASA}_{1}$ and $\mathrm{ASA}_{2}$. The dose of each sample was taken separately ranging from 0.02 to $0.12 \mathrm{~g}$ at $\mathrm{pH} 7.06$ for sample $\mathrm{AS}, \mathrm{pH} 6.7$ for sample $\mathrm{ASA}_{2}$ and $\mathrm{pH}$ 6.1 for sample $\mathrm{ASA}_{1}$ at $25{ }^{\circ} \mathrm{C}$ for $16 \mathrm{~h}$ (equilibrium time). It was found that the \% removal of $\mathrm{CV}$ increased from $55 \%$ to $71.6 \%$

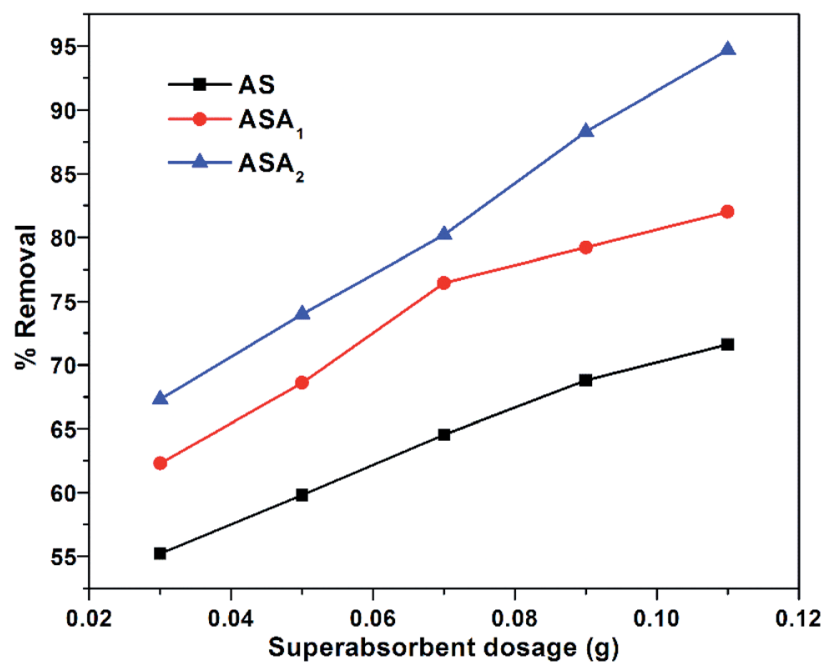

Fig. $4 \%$ removal as a function of dosage of superabsorbent hydrogels. Conditions: temperature: $25{ }^{\circ} \mathrm{C}$, equilibrium time: $16 \mathrm{~h}$, concentration of CV: $5 \mathrm{mg} \mathrm{L}^{-1}$, pH for: AS 7.05, $\mathrm{ASA}_{2} 6.1$ and $\mathrm{ASA}_{1} 6.7$. for $\mathrm{AS}, 62$ to $82 \%$ for $\mathrm{ASA}_{1}$ and 67.3 to $94.7 \%$ for $\mathrm{ASA}_{2}$ as indicated in Fig. 4 . This shows the increase in sorption capacity with increase in amount of superabsorbent hydrogels, which is due to the more swelling and availability of greater number of active sites with increase in dose of superabsorbent. Thus both diffusion and sorption are responsible for the removal of $\mathrm{CV}$ from the model solution.

3.3.3. Effect of contact time. Contact time effect of each sample was studied for \% removal of $\mathrm{CV}$ by taking different initial concentrations i.e. 3 ppm, 5 ppm, 7 ppm, 9 ppm and $11 \mathrm{ppm}$ of $\mathrm{CV}$ at $25^{\circ} \mathrm{C}$. The equilibrium contact time range was from 0.2 to $16 \mathrm{~h}$. The absorbed amount at any time $t\left(q_{t}, \mathrm{mg} \mathrm{g}^{-1}\right)$ was plotted against time $(t, \mathrm{~h})$ as shown in Fig. 5 . The rate of sorption was greater at first due to presence of large number of active sites on polymer network, but with the passage of time the sorption process is decreased due to occupation of active

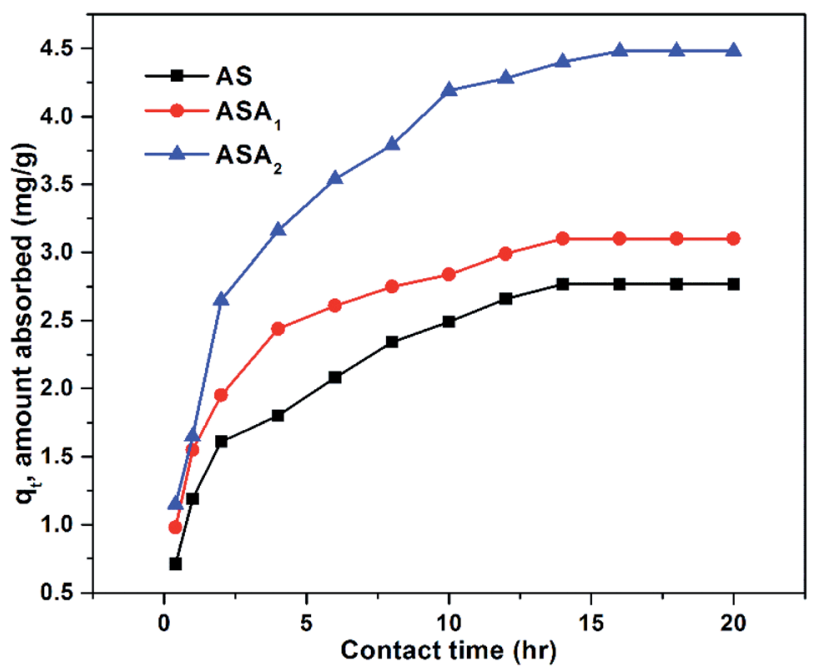

Fig. $5 q_{t}$ (amount absorbed at time $t$ ) as a function of contact time $(t)$. Conditions: initial concentration of CV: $9 \mathrm{mg} \mathrm{L}^{-1}$, temperature: $25^{\circ} \mathrm{C}$, pH for: AS 7.06, $\mathrm{ASA}_{1} 6.8$ and $\mathrm{ASA}_{2} 6.1$, superabsorbent hydrogel dose: $0.1 \mathrm{~g}$. 
sites by $\mathrm{CV}$ molecules and reduces the number of active sites for electrostatic interaction between dye molecules and that of superabsorbent hydrogel till equilibrium was established. The equilibrium time for $\mathrm{ASA}_{2}$ was $16 \mathrm{~h}$, and $14 \mathrm{~h}$ for AS and $\mathrm{ASA}_{1}$ samples. The difference in the equilibrium time was probably due to swelling pattern of samples and existence of AMPS monomer in polymer network.

3.3.4. Batch study. Batch experiments were performed to investigate the absorption capability of synthesized superabsorbent polymer hydrogels towards CV from aqueous solution. In this respect the different initial concentrations of $\mathrm{CV}$ i.e. 3 ppm, 5 ppm, 7 ppm, 9 ppm and 11 ppm were prepared and $20 \mathrm{ml}$ from each solution in $50 \mathrm{ml}$ bottles and mixed with each hydrogel sample ( $0.5 \mathrm{~g}$ of each adsorbent mass) separately. The concentration (ppm) of $\mathrm{CV}$ was found by measuring the absorption peak at $\lambda_{\max }=588 \mathrm{~nm}$ (the characteristic peak for $\mathrm{CV}$ ). The decrease in intensity of this peak occurs with time, which indicates the removal of $\mathrm{CV}$ from aqueous solution by superabsorbent hydrogels, and becomes constant at equilibrium. The absorption capacity or maximum amount of $\mathrm{CV}$ adsorbed $\left(q_{\mathrm{e}} \mathrm{mg} \mathrm{g}^{-1}\right)$ in sorption process by each sample was calculated using eqn (3);

$$
q_{\mathrm{e}}=\frac{\left(C_{\mathrm{o}}-C_{\mathrm{e}}\right)}{m} V
$$

where $q_{\mathrm{e}}\left(\mathrm{mg} \mathrm{g}^{-1}\right)$ is the maximum amount of $\mathrm{CV}$ absorbed in $\mathrm{mg} \mathrm{g}^{-1}$ by AS, $\mathrm{ASA}_{1}$ and $\mathrm{ASA}_{2}$ super absorbent hydrogels, $C_{\mathrm{o}}$ is the initial and $C_{\mathrm{e}}$ is the equilibrium concentration in $\mathrm{mg} \mathrm{L}^{-1}$ of

Table 1 Absorption capacity $q_{\mathrm{e}}\left(\mathrm{mg} \mathrm{g}^{-1}\right)$ and $\%$ removal of $\mathrm{AS}, \mathrm{ASA}_{1}$ and $\mathrm{ASA}_{2}$ towards $\mathrm{CV}$ at different initial concentration

\begin{tabular}{|c|c|c|c|c|c|c|}
\hline \multirow{2}{*}{$\begin{array}{l}\text { Initial concentration } \\
(\mathrm{ppm})\end{array}$} & \multicolumn{3}{|c|}{$q_{\mathrm{e}}\left(\mathrm{mg} \mathrm{g}^{-1}\right)$} & \multicolumn{3}{|c|}{$\%$ removal } \\
\hline & AS & $\mathrm{ASA}_{1}$ & $\mathrm{ASA}_{2}$ & AS & $\mathrm{ASA}_{1}$ & $\mathrm{ASA}_{2}$ \\
\hline 3 & 0.73 & 0.925 & 0.95 & 76 & 90.1 & 97.44 \\
\hline 5 & 1.15 & 1.47 & 1.55 & 71 & 85.2 & 95.2 \\
\hline 7 & 1.4 & 2.06 & 2.13 & 67 & 81 & 91.88 \\
\hline 9 & 1.51 & 2.64 & 2.73 & 64.1 & 77.3 & 84.23 \\
\hline 11 & 1.78 & 3.31 & 3.34 & 62.6 & 75 & 82.1 \\
\hline
\end{tabular}

the $\mathrm{CV}$ in liquid solution, $m(\mathrm{~g})$ is the amount of $\mathrm{AS}, \mathrm{ASA}_{1}$ and $\mathrm{ASA}_{2}$ used as an absorbent and $V$ is the volume (ml) of solution. The \% removal and $q_{\mathrm{e}}$ values were measured and tabulated in Table 1 . The obtained data indicates that the $q_{\mathrm{e}}$ increased from $0.733 \mathrm{mg} \mathrm{g}^{-1}$ to $1.78 \mathrm{mg} \mathrm{g}^{-1}$ for AS, $0.925 \mathrm{mg} \mathrm{g}^{-1}$ to $3.31 \mathrm{mg} \mathrm{g}^{-1}$ for $\mathrm{ASA}_{1}$ and $0.95 \mathrm{mg} \mathrm{g}^{-1}$ to $3.34 \mathrm{mg} \mathrm{g}^{-1}$ for $\mathrm{ASA}_{2}$, which shows that the absorbed amount of CV increases with the increase in initial concentration from 3 ppm to 11 ppm (Fig. 6a). On the other hand the \% removal of the CV decreases for all the three samples with increase in the initial concentration of CV from $3 \mathrm{ppm}$ to $11 \mathrm{ppm}$ (Fig. $6 \mathrm{~b}$ ) due to the occupying of the active sites of the adsorbent, while at low concentration (3 ppm) sufficient numbers of active surfaces are available for the removal and adsorption process. ${ }^{42}$

3.3.5. Kinetic study. The kinetic study for the synthesized samples $\mathrm{AS}, \mathrm{ASA}_{1}$ and $\mathrm{ASA}_{2}$ was performed by applying Lagergren pseudo first order and pseudo second order kinetics for CV removal during sorption process. The linear form of Lagergren pseudo first order kinetics is given in eqn (4);

$$
\ln \left(q_{\mathrm{e}}-q_{t}\right)=\ln Q_{\mathrm{e}}-k_{\mathrm{L}} t
$$

where $q_{\mathrm{e}}\left(\mathrm{mg} \mathrm{g}^{-1}\right)$ is the maximum absorbed amount of $\mathrm{CV}$ at equilibrium, $q_{t}\left(\mathrm{mg} \mathrm{g}^{-1}\right)$ is absorption at different intervals of time $(t)$ before equilibrium, while $k_{\mathrm{L} 1}\left(\mathrm{~min}^{-1}\right)$ is known as the rate constant of pseudo first order kinetics equation. The experimental data obtained was plotted between $\ln \left(q_{\mathrm{e}}-q_{t}\right)$ vs. $t$ (h) (Fig. 7) and the kinetic parameters $Q_{\mathrm{e}}$ and $k_{\mathrm{L} 1}$ were calculated from the intercept and slope of the graph respectively. The Table 2 denotes all the calculated values for pseudo first order kinetics. The clear and pronounced difference between experimental absorption capacity $\left(q_{\exp }\right)$ and calculated absorption capacity $\left(q_{\text {cal }}\right)$ of superabsorbent hydrogels (AS, $\mathrm{ASA}_{1}$ and $\mathrm{ASA}_{2}$ ) towards $\mathrm{CV}$ removal from aqueous solution indicates the deviation from pseudo first order kinetics. Also the irregularity in $k_{\mathrm{L} 1}$ values and low values of regression factor $\left(R^{2}\right)$ than unity confirms the deviation from the pseudo first order kinetics.

The obtained data was further interpreted by applying pseudo second order kinetics using a linear eqn (5);
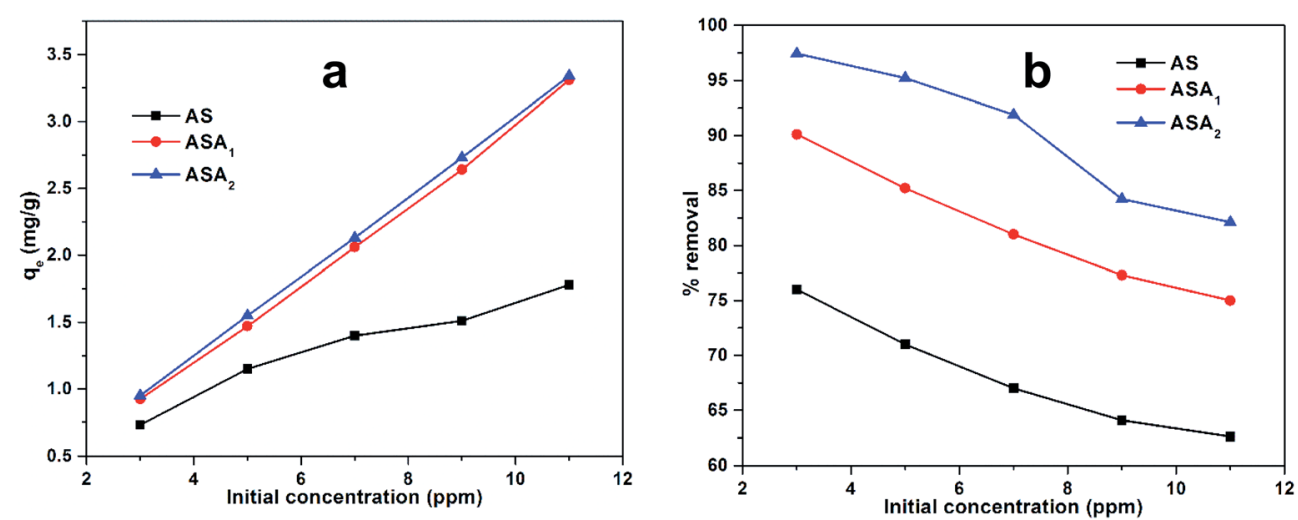

Fig. 6 (a) $q_{\mathrm{e}}\left(\mathrm{mg} \mathrm{g}^{-1}\right)$ and (b) \% removal as a function of initial concentration of CV used. 

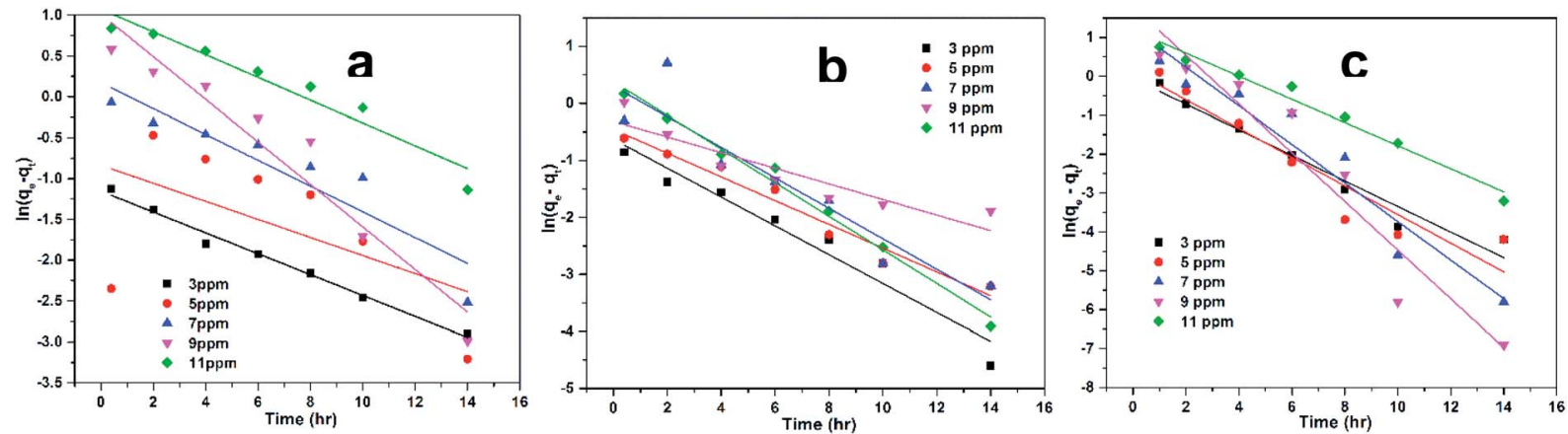

Fig. 7 Lagergren pseudo first-order kinetics for removal of CV by (a) AS, (b) $A S A_{1}$ and $(c) A_{2} A_{2}$ from aqueous solution with different initial concentration of $\mathrm{CV}$.

$$
\frac{t}{q_{t}}=\frac{1}{k_{2} q_{\mathrm{e}}}+\frac{t}{q_{\mathrm{e}}}
$$

where $k_{2}\left(\mathrm{~min}^{-1}\right)$ is the rate constant of second order kinetics. A plot was plotted between $t / q_{t} v s$. $t$ at different concentration for each superabsorbent hydrogel sample and the results are shown in Fig. 8. The unknown parameters were calculated from the slope and intercept of the equation and tabulated in Table 2. In this case the experimental $\left(q_{\exp }\right)$ and calculated $\left(q_{\text {cal }}\right)$ values for sample AS, $\mathrm{ASA}_{1}$ and $\mathrm{ASA}_{2}$ are in a close relation. Similarly, the regression factor $\left(R^{2}\right)$ are very close to unity, thus showed

Table 2 Calculated kinetic parameters for the removal of CV by superabsorbent hydrogels from aqueous medium

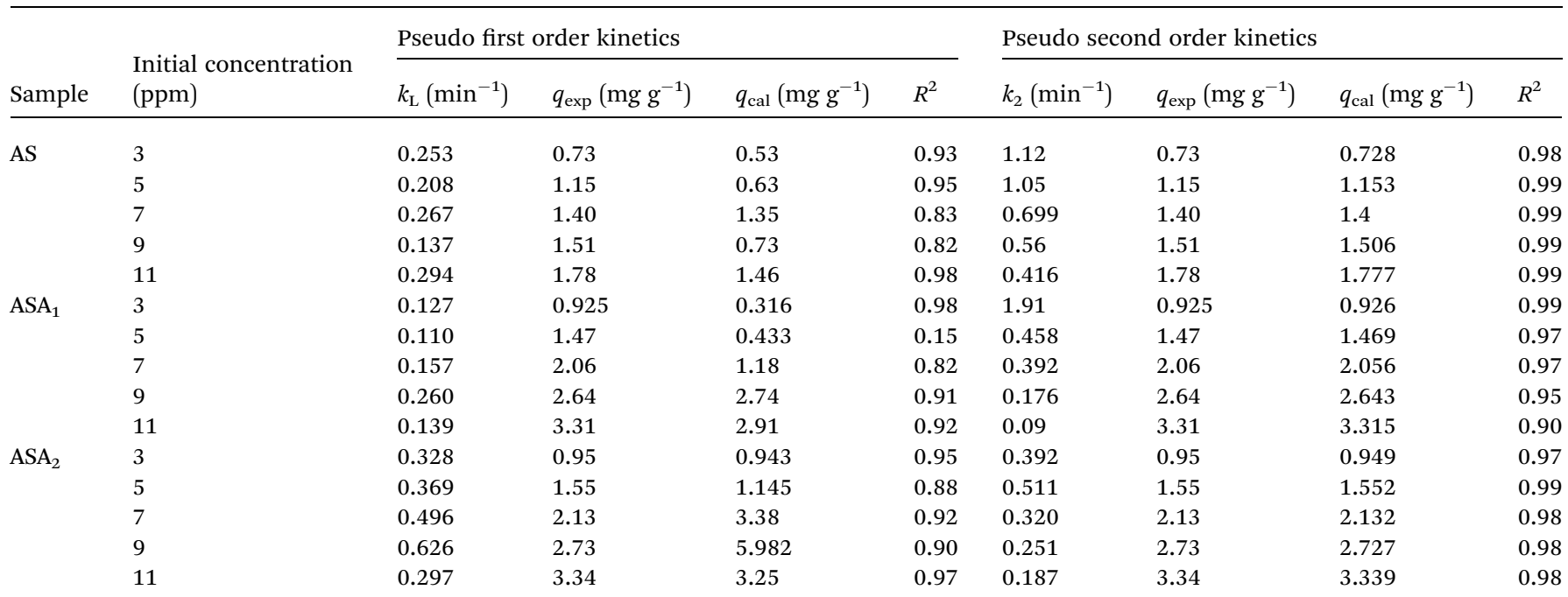
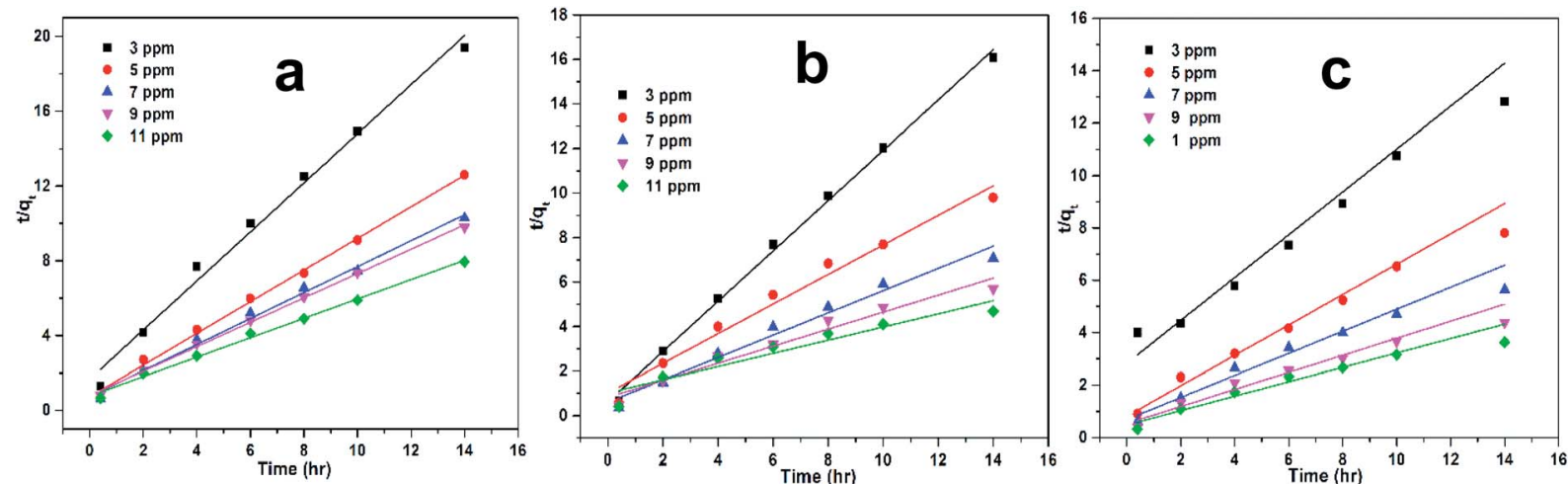

Fig. 8 Pseudo second order kinetics for removal of CV by (a) AS, (b) $A S A_{1}$ and (c) $A_{S A}$ from aqueous solution with different initial concentration of CV. 
that the data for all samples was best fit in pseudo second order kinetics.

\subsection{Sorption mechanism}

The Freundlich and Langmuir isotherms were applied to check the sorption mechanism of superabsorbent hydrogels towards the $\mathrm{CV}$ from aqueous solution. The models were investigated at temperatures 303, 308 and $313 \mathrm{~K}$, but for the present investigation the optimum temperature was selected.

3.4.1. Langmuir isotherm. Langmuir isotherm model is based on the monolayer formation of adsorbate (CV in this study) on the surface of adsorbent (superabsorbent hydrogels) and the mathematical expression is mentioned in eqn (6);

$$
\frac{C_{\mathrm{e}}}{q_{\mathrm{e}}}=\frac{1}{q_{\mathrm{m}} K_{\mathrm{L}}}+\frac{C_{\mathrm{e}}}{q_{\mathrm{m}}}
$$

where $C_{\mathrm{e}}\left(\mathrm{mg} \mathrm{L}^{-1}\right)$ is equilibrium concentration of $\mathrm{CV}$ in aqueous medium, $q_{\mathrm{e}}\left(\mathrm{mg} \mathrm{g}^{-1}\right)$ is the maximum amount of $\mathrm{CV}$ absorbed on adsorbent, $K_{\mathrm{L}}\left(\mathrm{L} \mathrm{g}^{-1}\right)$ is the Langmuir constant (free energy) and $q_{\mathrm{m}}\left(\mathrm{mg} \mathrm{\textrm {g } ^ { - 1 }}\right)$ is the adsorption capacity for monolayer formation of adsorbent. The experimental data was plotted in Fig. 9, the graph was obtained between $C_{\mathrm{e}} / q_{\mathrm{e}} v s . C_{\mathrm{e}}$, while the $K_{\mathrm{L}}$ and $q_{\mathrm{m}}\left(\mathrm{mg} \mathrm{g}^{-1}\right)$ values were calculated from the intercept and slope of the graph respectively. The Langmuir constant $\left(K_{\mathrm{L}}\right)$ gives information about the strength of interaction between adsorbate and absorbent. High the $K_{\mathrm{L}}$ value,

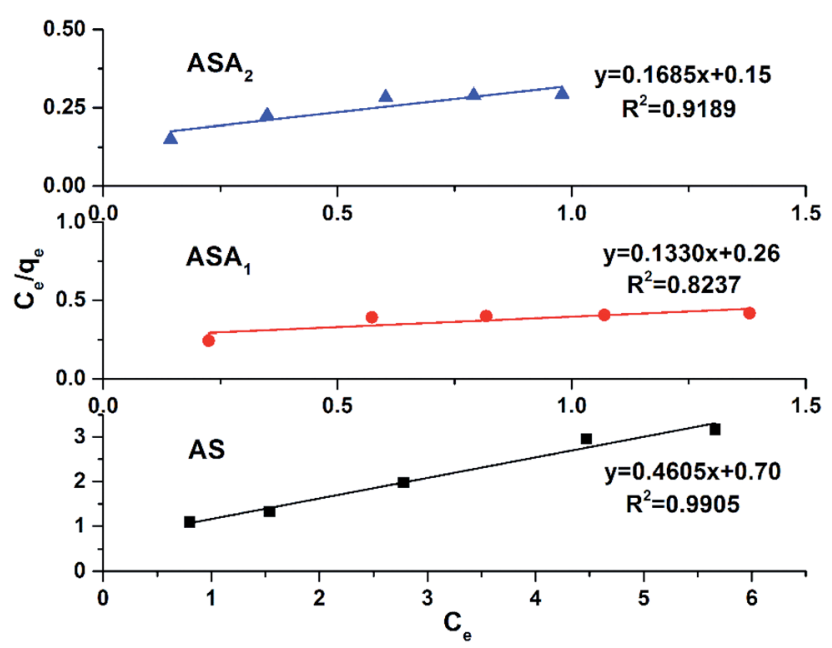

Fig. 9 Langmuir isotherm model for removal of CV from aqueous medium using superabsorbent hydrogels. stronger will be the interaction and vice versa. In this study, the $K_{\mathrm{L}}$ value for all superabsorbent hydrogel samples are very small (shown in Table 3), which shows weak extent of interaction between these materials and CV. Moreover, the less values of $R^{2}$ and the deviated theoretical $q_{\mathrm{e}}$ values from experimental $q_{\mathrm{e}}$ values clearly indicate that the sorption process not follows the Langmuir model (Table 3). However, the greater values of $\Delta H^{\circ}$ such as $249 \mathrm{~kJ} \mathrm{~mol}^{-1}$ for AS, $377 \mathrm{~kJ} \mathrm{~mol}^{-1}$ for $\mathrm{ASA}_{1}$ and $403 \mathrm{~kJ} \mathrm{~mol}^{-1}$ for $\mathrm{ASA}_{2}$ indicates the chemisorption interaction of the $\mathrm{CV}$ with superabsorbent hydrogels. The separation factor $\left(R_{\mathrm{L}}\right)$ for $\mathrm{AS}, \mathrm{ASA}_{1}$ and $\mathrm{ASA}_{2}$ was calculated by using eqn (7). The $R_{\mathrm{L}}$ values for all samples lies between 0 to 1 (Table 3 ), which shows that the process is favorable.

$$
R_{\mathrm{L}}=\frac{1}{1+K_{\mathrm{L}} C_{\mathrm{o}}}
$$

3.4.2. Freundlich isotherm. The data was further analyzed by Freundlich isotherm to check the mechanism of the removal of CV by superabsorbent hydrogels. Freundlich adsorption mechanism is based on multilayer formation and is not limited to monolayer of adsorbate on surface of adsorbent and heterogeneous in nature. All the samples data were plotted by using the logarithmic form of Freundlich isotherm as mentioned in eqn (8);

$$
\log q_{\mathrm{e}}=\log K_{\mathrm{F}}+\frac{1}{n} \log C_{\mathrm{e}}
$$

where $q_{\mathrm{e}}\left(\mathrm{mg} \mathrm{g}^{-1}\right)$ is the adsorption capacity of dye absorbed on absorbent, $C_{\mathrm{e}}\left(\mathrm{mg} \mathrm{L}^{-1}\right)$ equilibrium concentration of dye in aqueous medium, $K_{\mathrm{F}}\left(\mathrm{mg}^{\mathrm{g}^{-1}}\right)$ is the Freundlich adsorption constant, while $n$ indicates the adsorption intensity (Freundlich parameter). The $K_{\mathrm{F}}$ and $n$ values were calculated from the intercept and slope respectively by plotting $\log q_{\mathrm{e}} v s . \log C_{\mathrm{e}}$ as shown in Fig. 10 (Table 3). The higher the $K_{\mathrm{F}}$ value in comparision to $K_{\mathrm{L}}$ value (Langmuir constant) of all sample along with regression factor $R^{2}$ close to 1 , supported the dye removal mechanism by Freundlich isotherm model. However, the other parameter of the Freundlich model like value of $n$ further highlight the interface concentration within the solution, which can be justify by the $n$ values. When the $n$ value is greater than 1 , the process strongly support the sorption process. In this study the value of $n$ for all samples was greater than 1 such as for AS was 2.41, for sample $\mathrm{ASA}_{1}$ was 1.56 and for sample $\mathrm{ASA}_{2}$ the value was 1.43. Therefore we can conclude that the removal of $\mathrm{CV}$ from aqueous medium by superabsorbent hydrogels follows

\begin{tabular}{|c|c|c|c|c|c|c|c|c|c|}
\hline Samples & \multicolumn{5}{|c|}{ Langmuir isotherm } & \multicolumn{4}{|c|}{ Freundlich isotherm } \\
\hline $\mathrm{ASA}_{1}$ & 0.512 & 3.31 & 7.519 & 0.8237 & 0.073 & 3.169 & 1.56 & 0.641 & 0.994 \\
\hline $\mathrm{ASA}_{2}$ & 1.123 & 3.34 & 5.935 & 0.9189 & 0.043 & 2.455 & 1.43 & 0.700 & 0.986 \\
\hline
\end{tabular}
the Freundlich isotherm mechanism.

Table 3 The measured parameters with application of different isotherms 


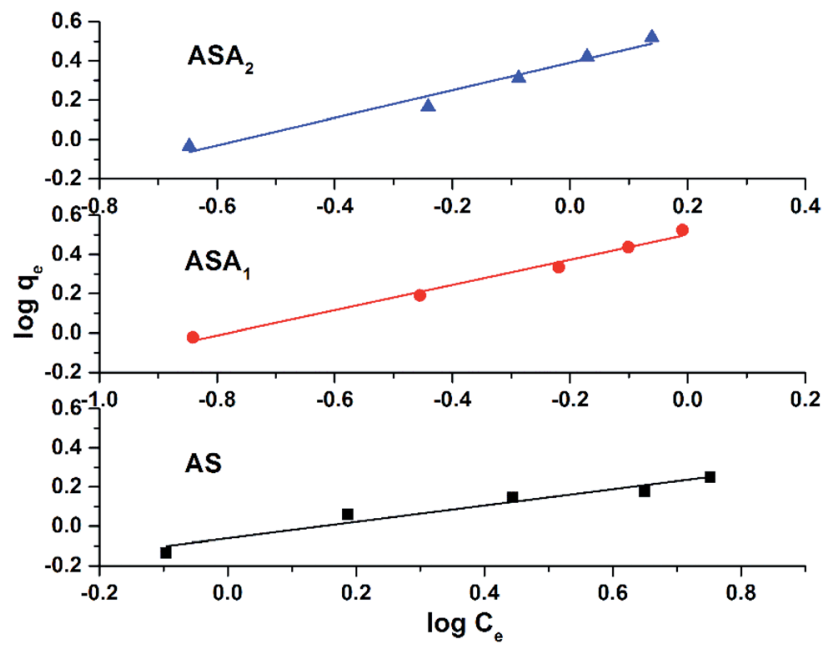

Fig. 10 Freundlich isotherm model for removal of CV from aqueous medium using superabsorbent hydrogels.

\subsection{Thermodynamics study}

The thermodynamic investigation was performed at different temperatures by measuring the thermodynamic parameters such as $\Delta G^{\circ}, \Delta H^{\circ}$ and $\Delta S^{\circ}$ by using Vont Hoff's equations (eqn (9) to (11)) given as;

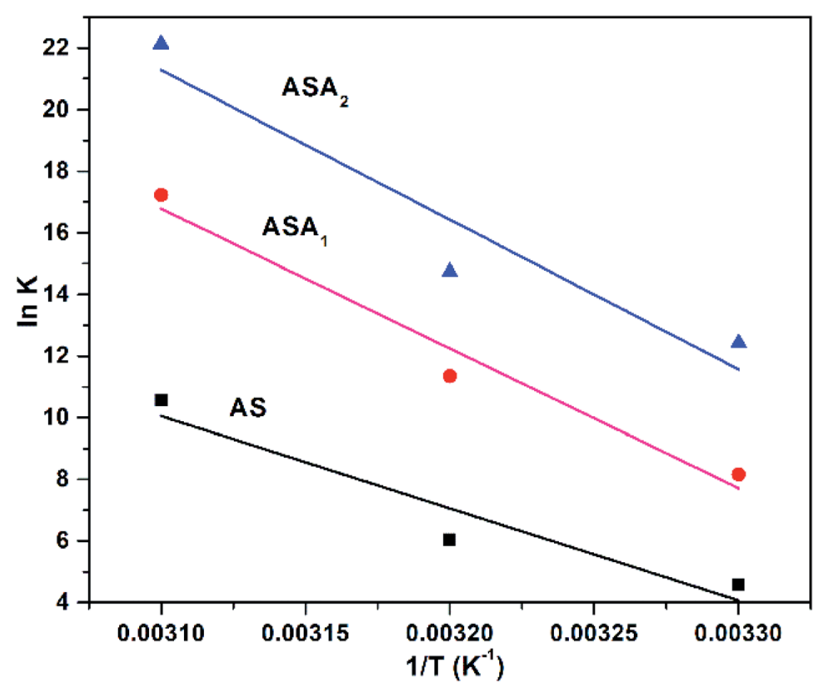

Fig. 11 Effect of temperature on absorption of $\mathrm{CV}$ by superabsorbent hydrogels. Conditions: dose $0.1 \mathrm{~g} ; \mathrm{pH} 9$ for $\mathrm{AS}, \mathrm{pH} 5.3$ for $\mathrm{ASA}_{1}$ and $\mathrm{pH}$ 6.8 for $\mathrm{ASA}_{2}$; temperature $303 \mathrm{~K}, 308 \mathrm{~K}$ and $313 \mathrm{~K}$.

$$
\begin{gathered}
\Delta G^{\circ}=\Delta H^{\circ}-T \Delta S^{\circ} \\
\Delta G^{\circ}=-R T \ln K \\
\ln K=\frac{\Delta S^{\circ}}{R}-\frac{\Delta H^{\circ}}{R T}
\end{gathered}
$$

where $T$ is the temperature in kelvin, $R$ is universal gas constant $\left(8.314 \mathrm{~kJ} \mathrm{~mol}^{-1} \mathrm{~K}^{-1}\right)$ and $K$ is the thermodynamic equilibrium constant, $\Delta S^{\circ}\left(\mathrm{J} \mathrm{mol}^{-1} \mathrm{~K}^{-1}\right), \Delta H^{\circ}\left(\mathrm{kJ} \mathrm{mol}^{-1}\right)$ and $\Delta G^{\circ}\left(\mathrm{kJ} \mathrm{mol}^{-1}\right)$ are change in entropy, enthalpy and Gibb's free energy, respectively. The Fig. 11 shows the graphical representation of the obtained data by potting $\ln K v s .1 / T$. The slope and intercept of the graph were used to calculate the values of $\Delta S^{\circ}$ and $\Delta H^{\circ}$ and tabulated in Table 4 . The $\Delta G^{\circ}$ was calculated by eqn (9) or (10), which confirms the spontaneity of the sorption process. Similarly, $K$ value was obtained by the ratio of $C_{\text {ads }} / C_{\mathrm{e}}$. The obtained positive value of enthalpy change for absorption process of $\mathrm{CV}$ dye by AS, $\mathrm{ASA}_{1}$ and $\mathrm{ASA}_{2}$ showed that the process is endothermic and the removal of $\mathrm{CV}$ increases with increase in temperature. Similarly, the positive value of entropy change indicated that the randomness in arrangement of dye molecules on superabsorbents with temperature changes. For this purpose the parameters for all samples were studied at three different temperatures i.e. $303 \mathrm{~K}, 308 \mathrm{~K}$ and $313 \mathrm{~K}$. The spontaneity of the process pattern is such that for AS the $\Delta G^{\circ}$ value changed from -178 to $-192 \mathrm{~kJ} \mathrm{~mol}^{-1}$, for $\mathrm{ASA}_{1}$ it was changed to -32.09 from $-19 \mathrm{~kJ} \mathrm{~mol}^{-1}$ and for $\mathrm{ASA}_{2}$ the value changed from -26.66 to $-40.83 \mathrm{~kJ} \mathrm{~mol}^{-1}$. This indicates that the removal of $\mathrm{CV}$ is less spontaneous by increasing temperature from $303 \mathrm{~K}$ to $313 \mathrm{~K}$. However, the spontaneity of sample AS is less as compared to $\mathrm{ASA}_{1}$ and $\mathrm{ASA}_{2}$ as shown in Table 4. Comparatively speaking the introduction of anionic monomer in sample $\mathrm{ASA}_{1}$ and $\mathrm{ASA}_{2}$ enhanced the thermodynamic parameters of superabsorbent hydrogels.

\subsection{Recycling performance}

The beauty of these superabsorbent hydrogels is the simple regeneration by removing the entrapped dye molecules from inside its network structure. For this purpose the dye entrapped superabsorbent hydrogels were treated with acetone via the solvent extraction method. This method is preferred and more appropriate than other methods because in this method the dye molecules not decompose and recovered in its correct initial state. The recycling performance of these superabsorbent hydrogels was investigated in six consecutive cycles and results are given in Fig. 12. The results indicate that less than 5\%

\begin{tabular}{|c|c|c|c|c|c|c|c|}
\hline \multirow[b]{2}{*}{ Sample } & \multirow[b]{2}{*}{ Initial conc. $\left(\mathrm{mg} \mathrm{L}^{-1}\right)$} & \multirow[b]{2}{*}{$\begin{array}{l}\Delta S^{\circ} \\
\left(\mathrm{J} \mathrm{mol}^{-1} \mathrm{~K}^{-1}\right)\end{array}$} & \multirow[b]{2}{*}{$\begin{array}{l}\Delta H^{\circ} \\
\left(\mathrm{kJ} \mathrm{mol}^{-1}\right)\end{array}$} & \multirow[b]{2}{*}{$R^{2}$} & \multicolumn{3}{|c|}{$\Delta G^{\circ}\left(\mathrm{kJ} \mathrm{mol}^{-1}\right)$} \\
\hline & & & & & $303 \mathrm{~K}$ & $308 \mathrm{~K}$ & $313 \mathrm{~K}$ \\
\hline $\mathrm{ASA}_{1}$ & 3 & 1.307 & 377 & 0.94 & -19.02 & -25.25 & -32.09 \\
\hline $\mathrm{ASA}_{2}$ & 3 & 1.42 & 403.6 & 0.83 & -26.66 & -33.76 & -40.83 \\
\hline
\end{tabular}
decrease in \% removal occurred in the sixth $\left(6^{\text {th }}\right)$ cycle in the

Table 4 Measured thermodynamic parameters for removal of CV by superabsorbent hydrogels 


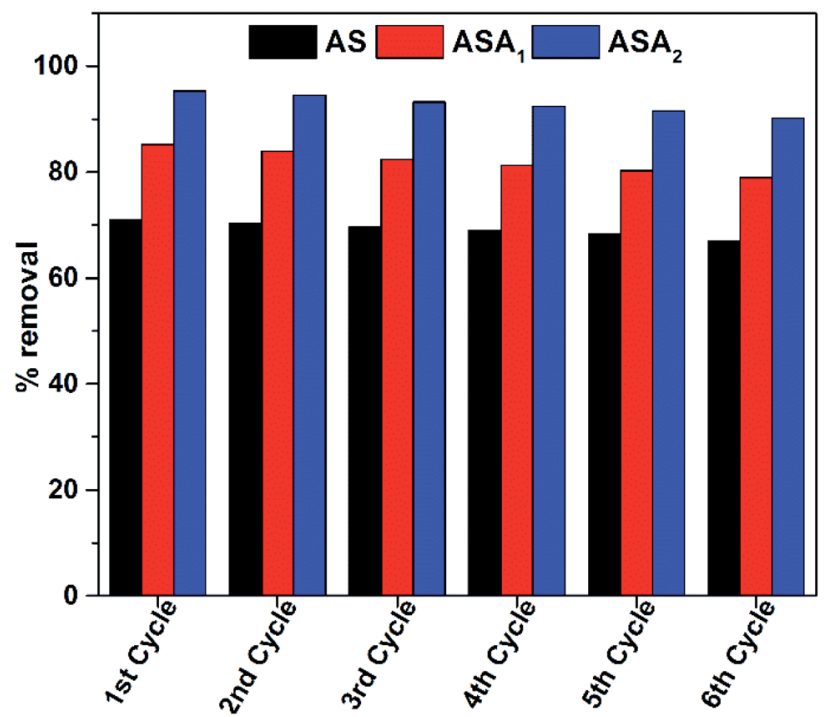

Fig. 12 Recycling performance of superabsorbent hydrogels towards CV removal.

recycling process. Which confirms the suitability of these materials to be used for the removal of pollutants from water at any condition.

\section{Conclusion}

Superabsorbent hydrogels of acrylamide/sodiumalginate (AS), acrylamide/sodiumalginate/2-acrylamido-2-methylpropane sulphonic acid ( $\mathrm{ASA}_{1}$ and $\mathrm{ASA}_{2}$ ) were successfully fabricated by free radical polymerization. The comparative study towards swelling behavior and removal of crystal violet (CV) from aqueous medium was studied in detail. The swelling ability of superabsorbents was found increased with the addition of AMPS in both distilled and tap water. The \% swelling for AS was 3685\%, which increased to $4797 \%$ for $\mathrm{ASA}_{1}$ and 21 175\% for $\mathrm{ASA}_{2}$ in distilled water, while in tap water, this property is varied from $915 \%$ for AS to $988 \%$ and $1588 \%$ for $\mathrm{ASA}_{1}$ and $\mathrm{ASA}_{2}$ respectively. All the samples were found more efficient in the sorption process of $\mathrm{CV}$ from aqueous medium with adsorption efficiency of $1.78 \mathrm{mg} \mathrm{g}^{-1}$ for AS with \% removal of $62.6 \%, 3.31 \mathrm{mg} \mathrm{g}^{-1}$ for $\mathrm{ASA}_{1}$ with $\%$ removal of $75 \%$ and $3.34 \mathrm{mg} \mathrm{g}^{-1}$ for $\mathrm{ASA}_{2}$ with $82.1 \%$ at $\mathrm{pH}>\mathrm{PZC}$ for particular sample. The samples kinetics data were best fitted in pseudo second order model, while the mechanism of sorption for all the samples followed Freundlich model. The thermodynamics parameters were investigated and the negative value of $\Delta G^{\circ}$ indicates the spontaneity of the process, while positive value of $\Delta H^{\circ}$ confirmed the endothermic nature of the process. Due to large swelling ability of $\mathrm{ASA}_{2}$, it showed efficient and better removal performance of $\mathrm{CV}$ compared to $\mathrm{ASA}_{1}$ and AS. Simple regeneration process, high recycling performance, easy synthesis, easy handling and nontoxic environmental friendly behavior make these materials a good candidate for waste water treatment.

\section{Conflicts of interest}

There are no conflicts of interest to declare.

\section{Acknowledgements}

L. A. Shah is highly thankful to Higher Education Commission (HEC) of Pakistan for financial support under research grant no. 7309 National Research Program for Universities (NRPU).

\section{References}

1 J. Núñez, M. Yeber, N. Cisternas, R. Thibaut, P. Medina and C. Carrasco, J. Hazard Mater., 2019, 371, 705-711.

2 G. C. de Oliveira Neto, J. M. F. Correia, P. C. Silva, A. G. de Oliveira Sanches and W. C. Lucato, J. Clean. Prod., 2019, 228, 1514-1525.

3 D. Krithika and L. Philip, Int. Biodeterior. Biodegrad., 2016, 107, 31-41.

4 M. Taheri, Surf. Interfaces, 2017, 9, 13-20.

5 S. Zhou, C. Di Paolo, X. Wu, Y. Shao, T.-B. Seiler and H. Hollert, Environ. Int., 2019, 128, 1-10.

6 N. González, M. Marquès, M. Nadal and J. L. Domingo, Food Chem. Toxicol., 2019, 125, 370-375.

7 K. Hunger, Industrial dyes: chemistry, properties, applications, John Wiley \& Sons, 2007.

8 R. S. Lokhande, P. U. Singare and D. S. Pimple, Resour. Environ., 2011, 1, 13-19.

9 P. A. Kobielska, A. J. Howarth, O. K. Farha and S. Nayak, Coord. Chem. Rev., 2018, 358, 92-107.

10 L.-M. Beckers, W. Busch, M. Krauss, T. Schulze and W. Brack, Water Res., 2018, 135, 122-133.

11 Y. Liu, Y. Nie, J. Wang, J. Wang, X. Wang, S. Chen, G. Zhao, L. Wu and A. Xu, Ecotoxicol. Environ. Saf., 2018, 162, 92-102.

12 F. Daoud, D. Pelzer, S. Zuehlke, M. Spiteller and O. Kayser, Chemosphere, 2017, 185, 953-963.

13 O. A. Alsager, M. N. Alnajrani, H. A. Abuelizz and I. A. Aldaghmani, Ecotoxicol. Environ. Saf., 2018, 158, 114122.

14 P. Gautam, S. Kumar and S. Lokhandwala, J. Clean. Prod., 2019, 117639.

15 M. A. Álvarez, M. Ruidíaz-Martínez, G. Cruz-Quesada, M. V. López-Ramón, J. Rivera-Utrilla, M. Sánchez-Polo and A. J. Mota, Chem. Eng. J., 2019, 122334.

16 L. A. Shah, A. Haleem, M. Sayed and M. Siddiq, J. Environ. Chem. Eng., 2016, 4, 3492-3497.

17 L. A. Shah, J. Mol. Liq., 2019, 288, 111045.

18 S. Yang, B. Gao, A. Jang, H. kyong Shon and Q. Yue, Chemosphere, 2019, 124485.

19 S. Lee, Y. Kim, J. Park, H. K. Shon and S. Hong, J. Membr. Sci., 2018, 556, 238-247.

20 C. Shen, Y. Zhao, W. Li, Y. Yang, R. Liu and D. Morgen, Chem. Eng. J., 2019, 372, 1019-1027.

21 Z. Yang, L. Liu, L. Zhao, G. Su, Z. Wei, A. Tang and J. Xue, J. Environ. Sci., 2019, 86, 24-37.

22 R. Javed, L. A. Shah, M. Sayed and M. S. Khan, RSC Adv., 2018, 8, 14787-14797.

23 A. Rahman, H. J. Hango, L. Daniel, U. Veikko, S. J. Jaime, S. V. Bhaskaruni and S. B. Jonnalagadda, J. Clean. Prod., 2019, 117689. 
24 E. Álvarez-Castillo, C. Bengoechea, N. Rodríguez and A. Guerrero, J. Clean. Prod., 2019, 223, 651-661.

25 Y. Kong, Y. Zhuang, Z. Han, J. Yu, B. Shi, K. Han and H. Hao, J. Environ. Sci., 2019, 78, 81-91.

26 Y. Zhuang and B. Shi, J. Environ. Sci., 2019, 85, 147-155.

27 T. Xiang, T. Lu, W.-F. Zhao and C.-S. Zhao, Langmuir, 2018, 35, 1146-1155.

28 T. U. Rehman, L. A. Shah, M. Khan, M. Irfan and N. S. Khattak, RSC Adv., 2019, 9, 18565-18577.

29 L. A. Shah, M. Khan, R. Javed, M. Sayed, M. S. Khan, A. Khan and M. Ullah, J. Clean. Prod., 2018, 201, 78-87.

30 M. Said, Y. Atassi, M. Tally and H. Khatib, J. Polym. Environ., 2018, 26, 3937-3948.

31 P. M. Pakdel and S. J. Peighambardoust, J. Environ. Manag., 2018, 217, 123-143.

32 J. Liu, X. Zheng and K. Tang, Rev. Adv. Mater. Sci., 2013, 33, 452-458.

33 J. Ren, F. Weber, F. Weigert, Y. Wang, S. Choudhury, J. Xiao, I. Lauermann, U. Resch-Genger, A. Bande and T. Petit, Nanoscale, 2019, 11, 2056-2064.
34 A. B. D. Nandiyanto, R. Oktiani and R. Ragadhita, Indonesian Journal of Science and Technology, 2019, 4, 97-118.

$35 \mathrm{~K}$. Elwakeel, A. El-Bindary, A. Ismail and A. Morshidy, J. Dispersion Sci. Technol., 2017, 38, 943-952.

36 M. J. Zohuriaan-Mehr and K. Kabiri, Iran. Polym. J., 2008, 17, 451.

37 B. H. Cipriano, S. J. Banik, R. Sharma, D. Rumore, W. Hwang, R. M. Briber and S. R. Raghavan, Macromolecules, 2014, 47, 4445-4452.

38 A. Riaz, N. M. Ranjha, A. Jalil, F. Sahar, M. S. Haider, H. S. Sarwar and F. Naeem, Lat. Am. J. Pharm., 2016, 35, 1378-1390.

39 A. Nesic, V. Panic, S. Ostojic, D. Micic, I. Pajic-Lijakovic, A. Onjia and S. Velickovic, Mater. Chem. Phys., 2016, 174, 156-163.

40 K. Kabiri, S. Faraji-Dana and M. J. Zohuriaan-Mehr, Polym. Adv. Technol., 2005, 16, 659-666.

41 M. El-Bindary, I. El-Deen and A. Shoair, J. Mater. Environ. Sci., 2019, 10, 604-617.

42 A. K. Meena, K. Kadirvelu, G. Mishraa, C. Rajagopal and P. Nagar, J. Hazard Mater., 2008, 150, 619-625. 